\title{
Learning Japanese Case: Overextensions and the Effects of Feedback
}

\author{
TAKAAKI SUZUKI \\ Kyoto Sangyo University
}

\section{Introduction}

In a highly elliptical language like Japanese, where argument NPs are frequently dropped from a sentence, children receive little information about case-markers (Rispoli 1991). Quite naturally, learning Japanese case-marking is a timeconsuming and error-driven process (Suzuki 1999). This study demonstrates that Japanese-speaking children often make overextension errors in case-marking, and that the errors are not easily corrected unless corrective feedback is continuously provided.

\section{Japanese case-markers}

In Japanese, grammatical relations are morphologically marked. Subjects of intransitive and transitive verbs are marked by the nominative $-g a$, and the direct object by the accusative $-O$ as shown in the following sentences.

(1) Taro-ga hasiru.

Taro-Nom run

'Taro runs.'

(2) Taro-ga Hanako-o hometa.

Taro-Nom Hanako-Acc praised

'Taro praised Hanako.'

Thanks to these case-markers, it is possible to identify the grammatical relations when the word order is changed into OSV as in (3) and when argument drop happens as in (4).

(3) Hanako-o Taro-ga hometa.

Hanako-Acc Taro-Nom praised

'Taro praised Hanako.' 
(4)

\author{
Taro-ga hometa. \\ Taro-Nom praised \\ 'Taro praised (X).' \\ Hanako-o hometa. \\ Hanako-Acc praised \\ '(X) praised Hanako.'
}

The Japanese case-marking system is explicit in the above sentences. However, case-markers are often unavailable in actual speech because argument ellipsis is very common, case-markers are often replaced with the topic particle $-w a$, and case-markers are sometimes dropped from argument NPs, referred to as case drop. If these phenomena happen in caregivers' speech, they are likely to cause a serious problem for children's learning of case-markers.

Analyzing caregivers' speech to Japanese-speaking children, Nakayama (1996) found that approximately $70 \%$ of parental speech to children involved argument drop. Rispoli (1991) also observed scant use of case-markers in parental speech. In his data, sentences involving nominative case-markers constitute only $8 \%$ of all intransitive sentences. In transitive sentences, nominative case-markers were used $4 \%$ of the time, accusative case-markers $7 \%$, and both nominative and accusative case-markers were used only $1 \%$ of the time. According to these observations, it is possible to suggest that Japanese-speaking children receive very little information about case-marking from parental input.

\title{
2. Previous studies on the acquisition of case-markers
}

Despite the fact that children receive little case-marking information, it is widely believed that Japanese case-markers are acquired at relatively early stages of language development. For example, Nagano (1959) and Okubo (1967) looked at the emergence of case-markers in the children's speech and suggested that case-markers are acquired at around age 2. More recent studies (Clancy 1985, Morikawa 1989) examined children's use of case-markers and found few case-marking errors in children's speech production.

However, I question this "almost error-free acquisition of case." This is because in children's spontaneous speech, argument drop is very common, case-markers are often replaced with other particles, and case-markers are often dropped from argument NPs. Taking them into consideration, I believe that even if children's knowledge of case-markers is unstable, it may not be seen as errors in their spontaneous speech. Therefore, it is ideal to investigate this issue in experimental situations.

\subsection{Experimental data on production (Suzuki 1999)}

Suzuki (1999) examined children's speech production of case-markers in an elicited production task performed by thirty preschool children. The results show that many case-marking errors were made, and that they were observed on the 
direct object more frequently than on the subject as shown in Table 1. It was also found that most of the case-marking errors were the overextension of the nominative case to the direct object as shown in Table 2.

Table 1 Percentages of case-marking errors

\begin{tabular}{ccc}
\hline & Subject & Object \\
\hline Younger & $14.8 \%$ & $46.6 \%$ \\
\hline Older & $7.9 \%$ & $27.9 \%$ \\
\hline
\end{tabular}

Table 2 Error types

\begin{tabular}{ccc}
\hline & Subject & Object \\
\hline Accusative/Nominative & $54(96.4 \%)$ & $174(93.5 \%)$ \\
\hline Other particles & $2(3.6 \%)$ & $12(6.5 \%)$ \\
\hline Total & $56(100 \%)$ & $186(100 \%)$ \\
\hline
\end{tabular}

\subsection{Experimental data on comprehension}

The production data in Suzuki (1999) imply that children treat direct objects as if they were subjects. However, there is also the possibility that children know the function of the accusative case but they for some reason do not produce the accusative case-marker. A comprehension task can test whether children treat the direct objects as subjects or whether they understand the functions of casemarkers but fail to produce the accusative case-marker.

Forty-four children aged between 3;1 and 6;2 (mean $=4 ; 7$ ) participated in the experiment. They were divided into two age groups: A younger group consisted of twenty-four 3- and 4-year-olds, and an older group twenty 5- 6-year-olds.

The child's task was to look at a picture where two animate entities were engaged in a certain action (e.g., hitting), and to answer the subject wh-question and the object $w h$-question as in (5).

$$
\begin{aligned}
& \text { subject } \text { wh-question } \\
& \text { Dare-ga tataita no? } \\
& \text { who-Nom hit Q } \\
& \text { 'Who hit (X)?' }
\end{aligned}
$$

\author{
object wh-question \\ Dare-o tataita no? \\ who-Acc hit Q \\ 'Whom did (X) hit?'
}

If the child understands the function of case-markers used in the test sentence, $\mathrm{s} /$ he can answer these questions correctly.

The results are summarized in Table 3. Incorrect responses were often observed, and they were more frequent for the object wh-question than for the subject $w h$-question. This asymmetry is consistent with the production task where children made case-marking errors more frequently for direct objects or the accusative case than for subjects or the nominative case. Thus, the results of the comprehension task suggest that preschool children's overextension errors in their speech production are due to their unstable knowledge of case-markers. 


\section{Takaaki Suzuki}

Table 3 Percentages of incorrect responses

\begin{tabular}{lll}
\hline & Subject & Object \\
\hline Younger & $14.6 \%$ & $71.4 \%$ \\
\hline Older & $3.1 \%$ & $40.0 \%$ \\
\hline
\end{tabular}

\section{Learning Japanese case-markers}

Two important questions arise from the results of the experiments reported above. One regards why children make overextension errors of the nominative case so frequently in comparison to other types of case-marking errors. The other is how children retreat from these errors in the end. As I have discussed the first question and made some suggestions in Suzuki (1999), I will now focus on the second question.

How children retreat from errors is commonly discussed in relation to a learnability problem: the investigation of abstract and universal properties of language not inducible from input. However, the target grammar dealt with here is not a typical instance of this issue for at least two reasons. First, Japanese case-markers are mostly language-particular phenomena. Learning phonological and morphological aspects of case-markers are not universal, and they seem to be independent of the acquisition of abstract Case (Suzuki 1999, see also Wexler et. al. 1998). Second, as has been observed, children make a lot of case-marking errors. Typical examples of abstract and universal properties of language, such as principles of UG, are believed to be error-free. However, in the case of Japanese case-markers, timing of the acquisition is rather late and the acquisition process involves making many errors.

For these reasons, I believe that learning Japanese case-markers is not a deductive process based on innate syntactic constraints. Rather, it seems to be oriented mostly by children's experience. Thus, it is worth exploring what types of parental input and adult responses contribute to children's learning of case-markers. As a first step to answering these questions, I have conducted two experiments that provide artificial learning circumstances where input data are controlled.

\section{Experiment 1: Effects of positive evidence}

Experiment 1 examines whether children can make use of positive evidence for the case-marking of newly learned verbs.

\subsection{Subjects}

The participants were seventeen Japanese-speaking preschool children whose ages ranged from $3 ; 1$ to $6 ; 1$ (mean age $=4 ; 10$ ). There were five 3 -year-olds, five 4-year-olds, three 5-year-olds, and four 6-year-olds.

\subsection{Materials and Procedure}

In order to test the children's knowledge of case-markers and their responses to adult input, I adopted an elicited production task by using a set of pictures and a 
doll called "the Judge." First, the child was taught a novel verb. Two pictures in Figure 1 were shown and the experimenter introduced muteru as a transitive verb. The experimenter mentioned two animals and the novel verb, and explained that the action depicted in the second picture is called mureru. A past form, mutetta, was also introduced to show that the novel word follows the verb's inflectional pattern in Japanese, but the experimenter never gave the child information about case-markers by dropping arguments. Then, the third picture in Figure 2 was shown where one of the animal entities is hidden with a black cover. The experimenter said, "We don't know who this is, can you ask the Judge who?" In the practice session, the child had been told that a doll named the Judge knew who the hidden animal was and that the Judge would give her/him a hint if the child asked appropriately.

Figure 1 The first two pictures to teach the novel verb muteru
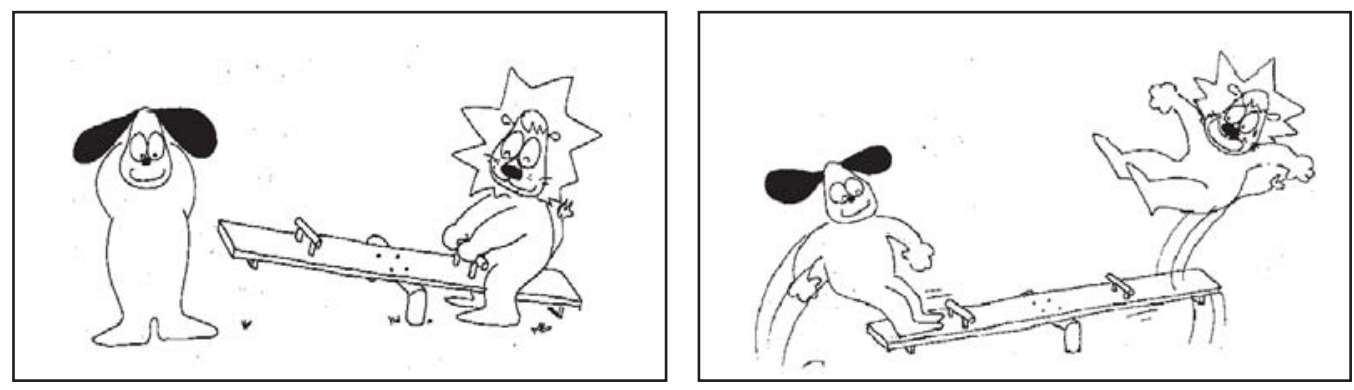

Figure 2 The third picture used to elicit the subject of muteru

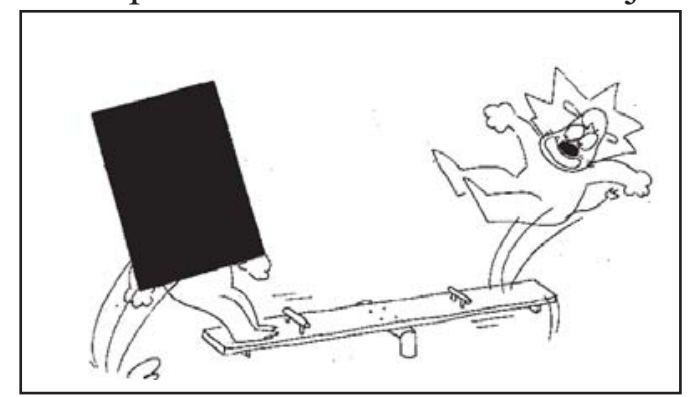

The child's task was to ask the Judge who the covered animal was by using a novel verb. The target utterances are shown in (6): the subject wh-question and the object $w h$-question. This situation is called the no input condition, because the child has not yet received case-marking information at the time $\mathrm{s} /$ he tries to produce a case-marker.

$$
\begin{aligned}
& \text { subject } w h \text {-question } \\
& \text { Dare-ga mutetta no? } \\
& \text { who-Nom verb Q }
\end{aligned}
$$

$$
\begin{aligned}
& \text { object wh-question } \\
& \text { Dare-o mutetta no? } \\
& \text { who-Acc verb Q }
\end{aligned}
$$

In response to the child's question, the Judge would give her/him a hint like "It's the one that says oink," and the child almost always got a correct answer. At this 
point, the experimenter gave the child the first evidence for the case-marking as in (7).

$$
\begin{array}{ll}
\text { So da ne. } & \text { Buta-ga mutettan da ne. } \\
\text { so cop pcl } & \text { pig-Nom verb cop pcl } \\
\text { 'Right!' } & \text { 'A pig did X.' }
\end{array}
$$

This is considered positive evidence, and the effect of the positive evidence was tested immediately after (7) by eliciting the same sentence structure while showing the same picture for another set of unknown entities. This situation is called the positive evidence condition.

A total of three novel verbs were tested. Other verbs were rakeru meaning that $X$ having a certain device, directs it at $Y$ who becomes sweaty, and naneru meaning that $X$ jumps toward $Y$ and hits $Y$ with its head. The order of the three verbs and that of the arguments elicited were counterbalanced.

\subsection{Results}

All conversations were tape-recorded and the relevant portions were transcribed by the experimenter. The children's utterances for the question formation were then examined to see whether they were compatible with the target sentence structure shown in (8).

$$
w h \text {-word + particle verb question-marker? }
$$

Although the omission of the case-marker is not necessarily ungrammatical, for the purpose of investigating children's usage of case-markers, the omission of the case-marker was treated as a non-targeted sentence structure. At this point, it was found that three children consistently produced sentences that were not compatible with the target sentence structure. Therefore, they were excluded from further analysis. The remaining 14 children (mean age $=4 ; 9$ ) occasionally produced non-targeted sentences, but their utterances also involved the sentence structure consistent with (8); therefore, these sentences were examined as to whether correct case-markers were used.

Table 4 summarizes the number of target sentences and correct case-markers produced by the children in the no input condition and in the positive evidence condition. Overall, it is clear that the children produced the correct case-marker for the subject $w h$-question more frequently than for the object $w h$-question, and that there was no difference in their performance between the two conditions. This subject-object asymmetry in case-marking errors is consistent with the results of previous experiments for existing verbs. However, error rates on the direct objects are higher for the novel verbs in the present experiment than for existing verbs in previous experiments. Only one child used the accusative case correctly on the direct objects in the no input condition as well as in the positive evidence condition. 
Table 4 The number of target sentences and correct responses

\begin{tabular}{lcccc}
\hline & \multicolumn{2}{c}{ Subject } & \multicolumn{2}{c}{ Object } \\
\hline & Correct & Target & Correct & Target \\
\hline No input condition & $35(13)$ & $39(14)$ & $2(1)$ & $35(13)$ \\
\hline Positive evidence condition & $36(14)$ & $39(14)$ & $2(1)$ & $38(14)$ \\
\hline
\end{tabular}

The cumulative number of children is shown in the parentheses

A complex picture emerges when individual performance is examined for each of the three verbs. First, all fourteen children made case-marking errors in the no input condition, but only five of them changed their utterances in the positive evidence condition. In other words, most children persisted in their incorrect initial assumption even after correct positive evidence was provided. Second, as shown in Table 5, most case-marking errors were the overextension of the nominative case to the direct object, and only two children made other types of errors: overextension of the accusative (child \#4), and that of the dative $-n i$ (child \#9). There was also misuse of the topic particle $-w a$ on the subject by one child. Third, even if the children changed their utterances in the positive evidence condition, their errors rarely improved.

Table 5 Individual performance for three novel verbs in Experiment 1

\begin{tabular}{|c|c|c|c|c|c|c|c|c|c|c|c|c|c|}
\hline & & \multicolumn{4}{|c|}{ Verb 1} & \multicolumn{4}{|c|}{ Verb 2} & \multicolumn{4}{|c|}{ Verb 3} \\
\hline & & \multicolumn{2}{|c|}{ Subject } & \multicolumn{2}{|c|}{ Object } & \multicolumn{2}{|c|}{ Subject } & \multicolumn{2}{|c|}{ Object } & \multicolumn{2}{|c|}{ Subject } & \multicolumn{2}{|c|}{ Object } \\
\hline Child & Age & $\mathrm{NC}$ & PC & $\mathrm{NC}$ & $\mathrm{PC}$ & $\mathrm{NC}$ & $\mathrm{PC}$ & $\mathrm{NC}$ & $\mathrm{PC}$ & $\mathrm{NC}$ & $\mathrm{PC}$ & $\mathrm{NC}$ & $\mathrm{PC}$ \\
\hline 1 & $3 ; 1$ & $\mathrm{~N}$ & $\mathrm{~N}$ & $\mathrm{~N}$ & $\mathrm{~N}$ & $\mathrm{~N}$ & $\mathrm{~N}$ & $\mathrm{~N}$ & $\mathrm{~N}$ & $\mathrm{~N}$ & $\mathrm{~N}$ & $\mathrm{~N}$ & $\mathrm{~N}$ \\
\hline 2 & $3 ; 7$ & $\mathrm{~N}$ & $\mathrm{~N}$ & $\mathrm{~N}$ & $\mathrm{~N}$ & $\mathrm{~N}$ & $\mathrm{~N}$ & $\mathrm{z}$ & $\mathrm{Z}$ & $\mathrm{N}$ & $\mathrm{N}$ & $\mathrm{N}$ & $\mathrm{N}$ \\
\hline 3 & $3 ; 7$ & $\mathrm{~N}$ & $\mathrm{~N}$ & $\mathrm{~N}$ & $\mathrm{~N}$ & $\mathrm{z}$ & $\mathrm{N}$ & $\mathrm{N}$ & $\mathrm{N}$ & $\mathrm{N}$ & $\mathrm{N}$ & $\mathrm{N}$ & $\mathrm{z}$ \\
\hline 4 & $3 ; 8$ & $\mathrm{~N}$ & $\mathrm{~N}$ & ug & $\mathrm{N}$ & A & $\mathrm{N}$ & A & $\mathrm{A}$ & $\mathrm{N}$ & A & A & A \\
\hline 5 & $3 ; 11$ & $\mathrm{~N}$ & $\mathrm{~N}$ & $\mathrm{~N}$ & $\mathrm{~N}$ & $\mathrm{~N}$ & $\mathrm{~N}$ & $\mathrm{~N}$ & $\mathrm{~N}$ & $\mathrm{~N}$ & $\mathrm{~N}$ & $\mathrm{~N}$ & $\mathrm{~N}$ \\
\hline 6 & $4 ; 2$ & $\mathrm{~N}$ & $\mathrm{~N}$ & $\mathrm{~N}$ & $\mathrm{~N}$ & $\mathrm{~N}$ & $\mathrm{~N}$ & $\mathrm{~N}$ & $\mathrm{~N}$ & $\mathrm{~N}$ & $\mathrm{~N}$ & $\mathrm{~N}$ & $\mathrm{~N}$ \\
\hline 7 & $4 ; 7$ & $\mathrm{~N}$ & $\mathrm{~N}$ & $\mathrm{~N}$ & $\mathrm{~N}$ & $\mathrm{~N}$ & $\mathrm{~N}$ & $\mathrm{~N}$ & $\mathrm{~N}$ & $\mathrm{~N}$ & $\mathrm{~N}$ & $\mathrm{~N}$ & $\mathrm{~N}$ \\
\hline 8 & $4 ; 10$ & $\mathrm{~N}$ & $\mathrm{~N}$ & $\mathrm{rc}$ & $\mathrm{N}$ & $\mathrm{N}$ & $\mathrm{N}$ & $\mathrm{rc}$ & $\mathrm{N}$ & $\mathrm{N}$ & $\mathrm{N}$ & $\mathrm{N}$ & $\mathrm{N}$ \\
\hline 9 & $5 ; 8$ & $\mathrm{~T}$ & $\mathrm{~N}$ & $\mathrm{D}$ & $\mathrm{D}$ & $\mathrm{T}$ & $\mathrm{T}$ & $\mathrm{D}$ & $\mathrm{D}$ & $\mathrm{T}$ & $\mathrm{T}$ & $\mathrm{D}$ & $\mathrm{D}$ \\
\hline 10 & $5 ; 9$ & $\mathrm{~N}$ & $\mathrm{~N}$ & $\mathrm{~N}$ & $\mathrm{~N}$ & $\mathrm{~N}$ & $\mathrm{~N}$ & $\mathrm{~N}$ & $\mathrm{~N}$ & $\mathrm{~N}$ & $\mathrm{~N}$ & $\mathrm{~N}$ & $\mathrm{~N}$ \\
\hline 11 & $5 ; 9$ & $\mathrm{Z}$ & $\mathrm{z}$ & $\mathrm{Z}$ & $\mathrm{z}$ & $\mathrm{z}$ & $\mathrm{z}$ & $\mathrm{z}$ & $\mathrm{z}$ & $\mathrm{N}$ & $\mathrm{z}$ & $\mathrm{Z}$ & $\mathrm{N}$ \\
\hline 12 & $6 ; 0$ & $\mathrm{~N}$ & $\mathrm{~N}$ & $\mathrm{~N}$ & $\mathrm{~N}$ & $\mathrm{~N}$ & $\mathrm{~N}$ & $\mathrm{~N}$ & $\mathrm{~N}$ & $\mathrm{~N}$ & $\mathrm{~N}$ & $\mathrm{~N}$ & $\mathrm{~N}$ \\
\hline 13 & $6 ; 1$ & $\mathrm{~N}$ & $\mathrm{~N}$ & $\mathrm{~N}$ & $\mathrm{~N}$ & $\mathrm{~N}$ & $\mathrm{~N}$ & $\mathrm{~N}$ & $\mathrm{~N}$ & $\mathrm{~N}$ & $\mathrm{~N}$ & $\mathrm{~N}$ & $\mathrm{~N}$ \\
\hline 14 & $6 ; 1$ & $\mathrm{~N}$ & $\mathrm{~N}$ & $\mathrm{~N}$ & $\mathrm{~N}$ & $\mathrm{~N}$ & $\mathrm{~N}$ & $\mathrm{~N}$ & $\mathrm{~N}$ & $\mathrm{~N}$ & $\mathrm{~N}$ & $\mathrm{~N}$ & $\mathrm{~N}$ \\
\hline $\mathrm{No}$ & & & & & & Cu & & & & סח & $\operatorname{ark}$ & & \\
\hline$:$ Pos & & & & & & itive & & & & Kelc & ve & se & \\
\hline Nomi & ive & & & & $\mathrm{T}:{ }^{-}$ & pic-1 & arke & & & & & al & ite \\
\hline
\end{tabular}

In order to investigate how the positive evidence affected the children's performance, I will focus on five children who changed their utterances after positive evidence was provided. They are children \#3, 4, 8, 9, and 13. Among them, four children (children $\# 3,4,8$, and 11) seem to have recognized what the 
target sentence structure was after positive evidence was given. For example, for the elicitation of the object $w h$-question in the no input condition, child \#4 initially produced an ungrammatical sentence like in (9). Similarly, child \#8 produced a relative clause construction as in (10) for two verbs.

$$
\begin{aligned}
& \text { * Raketta wa dare? } \\
& \text { verb -Top who }
\end{aligned}
$$

$$
\begin{aligned}
& \text { Raketta no wa dare? } \\
& \text { verb one Top who } \\
& \text { 'Who is the one that was raketta?' }
\end{aligned}
$$

(11) Dare-ga raketta no?

(12) Dare raketta no?

However, after they heard the experimenter's modeled speech, they changed their sentence structure to an NP $+\mathrm{V}$ pattern as in (11), although they did not use correct case-markers. Also, children \#3 and \#11 initially produced a sentence without a case-marker as in (12), but then started to use it in the positive evidence condition. However, a reverse pattern was also observed for the same children (\#3 and \#11) for the other verbs and thus their performance may not have actually been affected by the positive evidence. In general, positive evidence is likely to help the child to recognize the target sentence structure, but it may not help the child to implement the correct case-markers.

However, there were two cases where positive evidence worked for the children's correct case-marking. Child \#4 incorrectly used the accusative case for the subject of verb 3 in the no input condition, but he used the nominative in the positive evidence condition. Child \#9 used the topic particle for the subject of verb 1 before positive evidence was given, but after receiving the positive evidence he used the nominative case correctly. Note that both cases here were limited to the nominative case-marker on subjects.

In sum, positive evidence may simply help the child to recognize the target sentence structure, but there are individual variations in children. However, it was not sufficient for correcting children's case-marking errors in most cases, since many children persisted in incorrect case-marker(s) even after they received positive evidence.

\section{Effects of negative evidence}

Experiment 2 investigates the effects of negative evidence. Negative evidence generally refers to the information of ungrammaticality about a sentence, including disapproval, clarification requests, and explicit correction. However, I will use the term "negative evidence" as defined by Saxton (1997:145) as shown in (13). 


\section{Learning Japanese Case}

(13) Negative evidence: Negative evidence occurs directly contingent on a child error, (syntactic or morphosyntactic), and is characterized by an immediate contrast between the child error and a correct alternative to the error, as supplied by the child's interlocutor, as in (14).

(14) Child: He shooted the fish.

Adult: He shot the fish!

According to Saxton (1997), the negative evidence provided immediately after the child's error highlights the contrast between the child's error and the correct form. His experimental study demonstrates that English-speaking children can learn the irregular past tense form of novel verbs when negative evidence is given. In the present experiment, I will investigate whether negative evidence works for Japanese-speaking children's learning of a case-marker.

\subsection{Subjects}

The participants were 6 preschool children whose ages ranged from 3;7 to $5 ; 9$ (mean age $=4 ; 6$ ). There were two children each in the 3-, 4-, and 5-year-old ranges.

\subsection{Materials and Procedure}

This experiment adopted the same materials and procedure as in the first experiment, but the experimenter's reaction to the child's first trial was different. In this experiment, when a child produced an incorrect wh-question, the experimenter reacted as in (15) by contrasting the correct case-marker with the child's incorrect one.

Child: Dare-ga mutetta no?

Exp: Dare-o mutetta ka kite mite?

'Why don't you ask (him) whom (he) did X?'

If the child's error was not corrected by this feedback, the experimenter continued to have the same reaction to give the correct case-marker to the child. The case-marker examined in this experiment was focused on the accusative on the direct object of three novel verbs.

\subsection{Results}

Table 6 summarizes the results and Table 7 shows the individual data. In the no input condition, no child produced the accusative case on the direct object, and 4 children produced the target sentence structure. Non-targeted structures included the omission of a case-marker and an ungrammatical sentence. When the first negative evidence was provided, no child improved, although there was one more child who started to produce the target sentence structure. As in the case of the positive evidence condition in the first experiment, children persisted in using the 


\section{Takaaki Suzuki}

incorrect case-marker, the nominative $-g a$ for direct objects, even when they heard the accusative case in the experimenter's speech. Contrary to Saxton's results, no child benefited from the negative evidence immediately after the negative evidence was provided.

Table 6 The number of target sentences and correct responses

\begin{tabular}{lcc}
\hline & \multicolumn{2}{c}{ Object case-marking } \\
\hline & Correct & Target \\
\hline No input condition & 0 & $12(4)$ \\
\hline $1^{\text {st }}$ negative evidence & 0 & $10(5)$ \\
\hline $2^{\text {nd }}$ negative evidence & $3(1)$ & $15(6)$ \\
\hline $3^{\text {rd }}$ negative evidence & $4(3)$ & $9 / 9(4)$ \\
\hline
\end{tabular}

The cumulative number of children is shown in the parentheses

However, the negative evidence had some effects for some children when it was given continuously. Child \#6 started to produce the accusative case-marker after the second negative evidence was given, although she omitted the case-marker in the no input condition and in the first negative evidence condition.

Table 7 Individual performance for three novel verbs in Experiment 2

\begin{tabular}{|c|c|c|c|c|c|c|c|}
\hline Child \# & & 1 & 2 & 3 & 4 & 5 & 6 \\
\hline Age & & $3 ; 7$ & $3 ; 7$ & $4 ; 1$ & $4 ; 9$ & $5 ; 4$ & $5 ; 9$ \\
\hline \multirow[t]{5}{*}{ Verb 1} & No input & $\mathrm{N}$ & $\mathrm{N}$ & $\mathrm{N}$ & $z$ & $\mathrm{~N}$ & $\mathrm{z}$ \\
\hline & $1^{\text {st }}$ negative & $\mathrm{z}$ & $\mathrm{N}$ & $\mathrm{N}$ & $\mathrm{N}$ & $\mathrm{N}$ & $\mathrm{z}$ \\
\hline & $2^{\text {nd }}$ negative & $\mathrm{N}$ & $\mathrm{N}$ & $\mathrm{N}$ & $\mathrm{N}$ & $\mathrm{N}$ & A \\
\hline & $3^{\text {rd }}$ negative & --- & A & $\mathrm{N}$ & --- & $\mathrm{N}$ & -- \\
\hline & $\begin{array}{l}\text { number of input } \\
\text { required }\end{array}$ & --- & 3 & --- & --- & --- & 2 \\
\hline \multirow[t]{5}{*}{ Verb 2} & No input & $\mathrm{N}$ & $\mathrm{N}$ & $\mathrm{N}$ & $\mathrm{z}$ & $\mathrm{N}$ & $\mathrm{z}$ \\
\hline & $1^{\text {st }}$ negative & $\mathrm{np}$ & $\mathrm{N}$ & $\mathrm{N}$ & ug & $\mathrm{N}$ & $\mathrm{z}$ \\
\hline & $2^{\text {nd }}$ negative & $\mathrm{N}$ & $\mathrm{N}$ & $\mathrm{N}$ & ug & $\mathrm{N}$ & A \\
\hline & $3^{\text {rd }}$ negative & --- & $\mathrm{A}$ & --- & $\mathrm{A}$ & --- & --- \\
\hline & $\begin{array}{c}\text { number of input } \\
\text { required }\end{array}$ & --- & 3 & --- & 3 & --- & 2 \\
\hline \multirow[t]{5}{*}{ Verb 3} & No input & $\mathrm{N}$ & $\mathrm{N}$ & $\mathrm{N}$ & ug & $\mathrm{N}$ & $\mathrm{z}$ \\
\hline & $1^{\text {st }}$ negative & $\mathrm{N}$ & $\mathrm{ug}$ & $\mathrm{N}$ & $\mathrm{z}$ & $\mathrm{N}$ & $\mathrm{z}$ \\
\hline & $2^{\text {nd }}$ negative & $\mathrm{N}$ & ug & $\mathrm{N}$ & $\mathrm{z}$ & $\mathrm{N}$ & A \\
\hline & $3^{\text {rd }}$ negative & --- & $\mathrm{N}$ & $\mathrm{N}$ & $\mathrm{A}$ & $\mathrm{N}$ & --- \\
\hline & $\begin{array}{c}\text { number of input } \\
\text { required }\end{array}$ & --- & --- & --- & 3 & --- & 2 \\
\hline
\end{tabular}

$\mathrm{N}$ : Nominative

A: Accusative z: Zero-marking

np: not produced ug: ungrammatical sentence 


\section{Learning Japanese Case}

After being given negative evidence for the third time, child \#1 refused to try for all three verbs. Child \#6 answered correctly on the second try, and the other four children (children $\# 2,3,4$, and 5) gave responses to the third negative evidence. The results were that two children (children \#2 and 4) could use the accusative case for two of the verbs. This suggests that the overextension errors of the nominative case on direct objects could eventually be corrected by negative evidence.

As in the case of the positive evidence, the immediate effect of the negative evidence in Saxton's (1997) sense was not observed for accusative case-marking. However, both positive evidence and the negative evidence had a certain effect on the children's utterances. Some children who initially produced ungrammatical sentences seem to have learned that the novel word is a verb and how it is used in the target sentence structure.

\section{Conclusion}

From the results of the experiments, I would like to suggest that neither positive nor negative evidence is powerful enough for the children to learn how to use correct case-markers for novel verbs. There are two cases where the nominative case-marker was implemented due to the effect of positive evidence. On the other hand, the accusative case-marker was never used correctly immediately after either positive or the negative evidence was provided. The children's persistence to the nominative case is very strong, and it is not easy to correct their initial assumption unless negative evidence is continuously given.

\section{Acknowledgements}

This work was supported by Grant-in-Aid for Young Scientists (B) 14710383 from The Ministry of Education, Culture, Sports, Science and Technology (MEXT), Japan.

\section{References}

Clancy, Patricia. 1985. The acquisition of Japanese. In D. I. Slobin (ed.) The Crosslinguistic Study of Language Acquisition: The Data, 373-524. Hillsdale, NJ: Lawrence Erlbaum.

Morikawa, Hiromi. 1989. Acquisition of case marking and predicate-argument structures in Japanese: A longitudinal study of language acquisition mechanisms. Ph.D. dissertation, University of Kansas.

Nagano, Masaru. 1959. Youzi no gengo hattatu ni tuite: Syu to site zyosi no shuutoku-katei o tyuusin ni [On child language development: The acquisition of particles]. Kotoba no Kenkyuu Dai 1-syuu, 383-396. Tokyo, The National Language Research Institute. 
Nakayama, Mineharu. 1996. Acquisition of Japanese Empty Categories. Tokyo, Kuroshio.

Okubo, Ai. 1967. Youzi-gengo no Hattatu [Child Language Development]. Tokyo, Tokyodo.

Rispoli, Matthew. 1991. The acquisition of verb subcategorization in a functionalist framework. First Language 11: 41-63.

Saxton, Matthew. 1997. The contrast theory of negative input. Journal of Child Language 24: 139-161.

Suzuki, Takaaki. 1999. Two aspects of Japanese case in acquisition. Ph.D. dissertation, University of Hawaii at Manoa.

Wexler, Kenneth, Carson T. Schütze, and Mabel Rice. 1998. Subject case in children with SLI and unaffected controls: Evidence for the Agr/Tns omission model. Language Acquisition 7: 317-344.

Takaaki Suzuki

Department of Foreign Languages

Kyoto Sangyo University

Motoyama Kamigamo

Kita-ku, Kyoto 603-8555

Japan

takaaki@cc.kyoto-su.ac.jp 